\title{
The Silenced and Unsought Beneficiary: Investigating Epistemic Injustice in the Fiduciary
}

\author{
Helen Mussell \\ Cardiff University \\ University of Cambridge
}

\begin{abstract}
This article uses philosopher Miranda Fricker's work on epistemic injustice to shed light on the legal concept of the fiduciary, alongside demonstrating the wider contribution Fricker's work can make to business ethics. Fiduciary, from the Latin fìūcia, meaning "trust," plays a fundamental role in all financial and business organisations: it acts as a moral safeguard of the relationship between trustee and beneficiary. The article focuses on the ethics of the fiduciary, but from a unique historical perspective, referring back to the original formulation of the fiduciary within a familial context to investigate presuppositions regarding agential capabilities, whilst also paying attention to the power mechanism embedded in the trusteebeneficiary relationship. Using Fricker's theory of pre-emptive testimonial injustice, the analysis elucidates the impact of cumulative beneficiary silencing in contemporary contexts, and the article uncovers ethical issues of an epistemological kind at the core of the fiduciary-of epistemic injustice.
\end{abstract}

Key Words: fiduciary duty, epistemic injustice, Ethics of Care, shareholder activism, power, gender

$\mathrm{T}$ he legal concept of fiduciary, from the Latin fìducia, meaning "trust," plays a fundamental role in all financial and business organisations, as well as governing other professional relationships, including medical care. Fiduciary acts as a safeguard of the relationship between trustee and beneficiary, ensuring that the beneficiaries' best interests are met. The extent of the embeddedness of this legal concept in international financial and business architecture should not be underestimated. It has facilitated the ownership and movement of wealth through protection of capital and has undoubtedly played a leading role in the success of capitalism. Consequently, and as will become clear, the contribution of a critical analysis of the fiduciary has far-reaching implications for business ethics theory and practice.

There are a number of ongoing debates regarding the fiduciary, including whether the fiduciary comprises ethical and/or legal aspects (Laby 2005) and, specifically within an investment context, whether the fiduciary can accommodate socially responsible or ethical investment decisions being made by trustees on behalf of beneficiaries (Sandberg 2011, 2013; Richardson 2011). This article also focuses on the ethical aspect, but does so from a unique and historical perspective, going back to the original formulation of the fiduciary within a familial context not only to reveal 
why a duty of care plays a central role in the fiduciary but also to uncover key foundational presuppositions regarding agential capabilities embedded in the trustee-beneficiary relationship. In doing so, the article uncovers crucial ethical issues of an epistemological kind at the core of the fiduciary.

The article builds on existing work on the power relationship implicit in the fiduciary and its historical origins in gender relations (Richardson 2011; Mussell 2020) by using philosopher Miranda Fricker's (2009) insightful theory of epistemic injustice to explicate the position of the beneficiary. Fricker's work-as will become clear-offers the potential to make a significant contribution to business ethics owing to its focus on explicating epistemically excluded agents. These could include silenced stakeholders, excluded employees, or unconsulted shareholders-and as will be shown, all of these agents could be beneficiaries. This article, then, provides one example of how Fricker's work can be used to shine a light on a fundamental legal concept underpinning financial and business organisations.

By applying Fricker's theory of pre-emptive testimonial injustice to the position of the silenced beneficiary - whereby an agent's testimony is not only discredited due to implicit or explicit bias against the agent's identity but his or her testimony is not even sought because of his or her identity - the article confronts the foundations of the dyadic relationship at the core of the legal concept of the fiduciary. The application of Fricker's theory of pre-emptive testimonial injustice to the role of the beneficiary is also shown to help elucidate a number of contemporary issues where the fiduciary arrangement is prevalent - thus demonstrating the wide contribution her work can make to the field of business ethics. The first of these concerns why there are so few women in position of trusteeship. The second focuses on the increasing yet still relatively low levels of shareholder activism and engagement, or active ownership, of shareholders demanding their voices be heard. By theorising their silencing as pre-emptive testimonial injustice, the article highlights how shareholder activism is in fact rooted in issues concerning epistemic injustice. In light of this angle of the argument, the application of Fricker's thinking in the context of the article makes a significantly wide contribution to business ethics-not only to the literature focussing on fiduciary, corporate governance, and ethics (Gold and Milller 2014; Goldstone, McLennan, and Whitaker 2013; Miller 2014, 2018; Richardson 2011) but also to the body of work investigating shareholder activism (Fairfax 2019; Goodman and Arenas 2015; Cundill, Smart, and Wilson 2018; Coskun et al. 2018). Widening the analysis beyond the two specific examples- to take into account the extreme extent to which the fiduciary arrangement is embedded in our financial systems - the implications of Fricker's work on epistemic injustice for rethinking our current financial institutions, systems, and structures are discussed. Final thoughts regarding whether the fiduciary is in fact future-fit in light of the article's revelations are outlined.

\section{STRUCTURE}

To successfully demonstrate how Miranda Fricker's work can be used to contribute to business ethics by investigating epistemic injustice in the fiduciary, a brief 
introduction to existing work in the field of Kantian and Ethics of Care fiduciary ethics is outlined in Section 2. Alongside this, the importance of taking into account the historical development of the fiduciary, in order to understand the position of the beneficiary that Fricker's theory will elucidate, is emphasised. Lastly, the agential presuppositions implicit in the roles of trustee and beneficiary and the resultant power imbalance between the two positions are considered, laying the groundwork for the following sections' discussion, which constitutes the central focus of the article.

Section 3 engages with the position of the silenced beneficiary and further unpacks the aforementioned agential presuppositions. Miranda Fricker's theory of epistemic injustice and pre-emptive testimonial injustice are introduced, and their suitability for explicating the role of the beneficiary is highlighted. The implications and consequences of the epistemic exclusion or silencing of an epistemic agent are discussed.

The fourth and final section brings fiduciary back into a contemporary context. Drawing on insights from Fricker's work on the impact of cumulative pre-emptive testimonial injustice on epistemic agents - of persistently excluding their testimonies - an analysis of two contemporary contexts in which the fiduciary is prevalent is offered. The first of these examines the persistent gender disparity in positions of trusteeship held by women. The second focusses on shareholder activism and active ownership, and the argument is advanced that one reason for such activism is pushback rooted in issues concerning epistemic injustice. A discussion of the normative impact of the fiduciary relationship, how this ties to shareholder apathy, and what increasing shareholder activism reveals about this normativity are outlined. This discussion then leads to the crucial recognition that in light of the preceding revelations regarding the epistemic injustice embedded in the fiduciary, we must recognise the extent to which our financial structures and systems-in which the fiduciary in turn is fully embedded-are in fact embodiments of pre-emptive testimonial injustice.

Finally, the case is made that a future-fit fiduciary — or alternative arrangementrequires a realist rethink of agential capabilities, a re-emphasis on the trusteebeneficiary relationship, and a revisit to the good care ethics central to fiduciary.

\section{THE FIDUCIARY: A BRIEF INTRODUCTION TO ETHICAL AND HISTORICAL ASPECTS}

\subsection{A Kantian Framework for the Fiduciary}

A brief introduction to existing work in fiduciary ethics is necessary to lay the groundwork for the following analysis and to show how Fricker's contribution builds on and extends this ethical project. Work in this area has primarily focussed on the twin fiduciary duties of loyalty and care. Couched in the terminology of duty, a Kantian deontological framework is often used to explicate the fiduciary. Scholars proposing such an approach (Samet 2014; Laby 2005) focus on Kant's work concerning the duty of virtue, and their discussions include debates regarding whether the fiduciary duties of loyalty and care can be regarded as virtues. Laby's work goes 
a little further. He uses Kant's discussion to argue that both the judicial (loyalty) and ethical (care) aspects of the fiduciary contain a duty of virtue, and in doing so, he shores up arguments against increasing claims that the fiduciary is purely contractual and without ethical premises (Getzler 2014; Lydenberg 2014). ${ }^{1}$ He also draws attention to the importance of recognising changing historical legal contexts, noting that "a legal duty according to Kant, is not merely a legal duty as many use the term today, it is a moral duty that may be enforced by law" (Laby 2005, 3). The upshot of this for modern-day claims that the judicial aspect of fiduciary is amoral is that they fail to take into account that juridical laws also include the duty of virtue-they are a moral duty.

The use of a Kantian duty of virtue is then helpful in stemming the increasing erosion of fiduciary ethics, whilst also highlighting that the spirit of this legal concept is indeed ethical-important in the light of using Fricker's inherently ethical project. However, what is seemingly absent from the work of such scholars is a wider recognition of the socio-historical development of the fiduciary, including the conditions under which fiduciary relationships originated. Consequently, the source of the power dynamic embedded between trustees and beneficiaries and the longterm normative implications of this dynamic that Fricker's work will crucially reveal are overlooked, as are the related presuppositions regarding the agential capabilities of both parties. It is to these points that the focus now briefly turns.

\subsection{An Ethics of Care Framework for the Fiduciary}

As per the position defended elsewhere (see Mussell 2020), an investigation into the evolution of this legal concept-with particular attention paid to the implicit power mechanism embedded in the fiduciary relationship and its gendered originsreveals a great deal regarding its ethical narrative and points towards why care (notwithstanding wide interpretations thereof) is fundamental to the fiduciary. This focus on power is particularly important for the following use of Fricker's theory, which holds a conception of social power and its (mis)uses at its core.

Originally formulated within English common (familial) law as a means to protect property put into trust while the rightful (male) owner of the property ${ }^{2}$ was absent, for example, fighting in the Crusades, beneficiaries were women and children,

\footnotetext{
${ }^{1}$ The erosion of fiduciary ethics on the grounds that the judicial aspect of fiduciary is purely contractual is widely held to be the result of a neoclassical economic reading and influence on this legal concept. Laby's $(2005,1)$ observation that "over the past twenty years, law and economics scholars have argued that fiduciary duties can best be explained through the lens of contract" aligns with observations made by authors such as Getzler (2014), who pinpoints the Chicago School of Economics economist Ronald Coase as a central scholar guiding a "shift in the intellectual commitments of the legal caste" (Getzler 2014, 8) and of Steve Lydenberg (2014), who writes regarding constraining economic interpretations of the fiduciary.

${ }^{2}$ It should be noted that coverture (colloquially known as civil death) prevented English women from ownership of personal property upon marriage (personal property included money, stocks, furniture, jewellery, livestock, etc.) and also placed the control of their real property (housing and land), including rights to income earned from its lease, into their husbands' control (although the husband could not sell the property, as the wife retained legal ownership). Coverture was law from circa the twelfth century until 1870, when the Married Women's Property Act was passed. It should be noted that, in contrast, feme sole were legally permitted to own and control their own personal and real property. For further details, see Combs (2005).
} 
allocated passive and subordinated roles. As the lawyer Benjamin Richardson $(2011,6)$ writes, "trusts arose in England primarily to protect family wealth and to provide for the wife and children, who were socially constructed as passive and dependent. Modern investment law transplanted these arrangements for the private trust into a very different context." With this historical context in mind, the fiduciary arrangement can be seen to have been devised as a substitute for a familial relationship, one supposedly underpinned by care and taking place within the private sphere. Arguably, then, a more suitable ethical framework for explicating the ethics of fiduciary is an Ethics of Care (see Mussell 2020). This contemporary body of ethical theory originates from the work of Carol Gilligan, who sought to redress what she deemed to be biased studies in moral developmental psychology influenced by value-laden theory underpinned by certain interpretations of Kantian thinkingprioritising individualist-, rights-, and principle-centred ethics. Gilligan's work instead identified a different moral conception, and her work was noted for its other-regarding focus, highlighting interdependency and interconnection, and for being explicitly underpinned by a relational epistemology and ontology.

What arguably comes to the fore when thinking through the historical ethical development of the fiduciary using an Ethics of Care is that the trustee and beneficiary are clearly positioned within an interconnected relationship. The inherently relational Ethics of Care framework provides the potential to reframe the fiduciary as a relationship, not just as a duty. Speculating on why fiduciary has come to be known as a duty despite its origins as a substitute familial connection, Richardson highlights the role that the beneficiaries' subordination has played in this transformation from relationship to duty. He writes that "the idea that there is a relationship between the parties has been obscured because traditionally trust law cast beneficiaries into a passive role.... They traditionally have not enjoyed unqualified rights to be consulted or to instruct trustees on how they should undertake their responsibilities in the absence of legislative provisions" (Richardson 2011,6).

This is a crucial observation to note in light of the following analysis using Fricker's work, and the normative implications of beneficiaries not enjoying unqualified rights to be consulted — which Fricker's theory crucially exposes-will become clear. Richardson's comment also points directly at the causal role that presuppositions regarding the trustee and beneficiaries' agential capabilities, and the ensuing silencing of the beneficiary, has played in eroding the connection and relationship between the two fiduciary parties. Put differently, Richardson is claiming that the subordination of beneficiaries has not only undermined the fiduciary as a relationship but led to its evolution as being conceptualised as a disconnected duty. The reasoning behind why beneficiaries were cast into a passive, subordinated, and silenced role has been explored in detail elsewhere (Mussell 2020), but in brief, the presuppositions regarding agential capabilities embedded in the fiduciary are founded in false gender stereotypes that damage both men and women. These are stereotypes that often fall back onto trite dichotomies, constructing gendered identities along the now well-recognised erroneous lines of reason-emotion, rationalirrational, male-female, and so on, with an inherent hierarchy embedded in each dichotomy favouring the male-associated trait. The result of these presuppositions in 
the context of fiduciary has been an asymmetrical power dynamic embedded in its structure. Beneficiaries have not only had decision-making capacity removed but they have also been silenced within the fiduciary relationship. Trustees are not obliged to consult with beneficiaries to enquire of their needs or best interests, and as such, not only is their testimony deemed extraneous to the decision-making process but it is not even sought. It is to the task of considering the ethics of this silenced and excluded situation, and the light that Fricker's theory can shine on it, that we now turn.

\section{THE SILENCED AND UNSOUGHT}

As has been acknowledged in section 2, aspects of the Kantian fiduciary project are admirable for shoring up the ethical aspects of the fiduciary, successfully arguing that the remit of fiduciary reaches beyond the purely contractual and judicial. By arguing that both the duty of loyalty and the duty of care carry an ethical component, thereby laying the groundwork for the need to identify an ethical framework for fiduciary, solid ground is provided on which to lay out an alternative ethical explication of the fiduciary using the Ethics of Care. That said, the omission of the Kantian fiduciary project to go deeper and question why the beneficiary was even deemed to be in need of a trustee results in a failure to build in an account of why the beneficiary is essentially silenced and rendered voiceless or, in Richardson's terms, why beneficiaries "have not enjoyed unqualified rights to be consulted." These sorts of ethical questions, and the highlighted ensuing implications, sit squarely within the domain of epistemology. These are questions concerning the sort of knowledge individuals are presupposed to have, how and why they have such knowledge, the status afforded to knowledge, and whose opinion or testimony is sought as a result. And intersecting these lines of epistemological enquiry and the answers they evoke are ethical considerations. As a result, and to further investigate the outlined power dynamic inherent in the trustee-beneficiary relationship-particularly in light of the historical and gendered readings of its development-the work of the philosopher Miranda Fricker, specifically her book Epistemic Injustice: Power and the Ethics of Knowing (2009), is particularly useful in this context.

Fricker's work in the area of epistemology and ethics, which draws together epistemology and conceptualisations of justice, addresses a previous lacuna in the literature connecting the two fields. Her project sets out two central ideas of how social power and social disadvantage can result in epistemic injustice. One of these ideas Fricker terms as hermeneutical injustice - an ethical issue that arises when neither the epistemic agent (teller) nor the listener (receiver) is equipped with the necessary concepts to understand the situation or communication. The second idea Fricker outlines in her book is testimonial injustice.

\subsection{A Note on the Application of Fricker's Theory}

Before moving on to outline Fricker's theory, a brief word regarding its application would be beneficial. As already highlighted, Fricker's work helped address a lacuna in the ethics-epistemology literature, connecting the two fields via considerations of 
social power. But this does not mean that a spotlight had not previously been shone on the social power interplay affecting epistemologies and positions of knowing. Indeed, Fricker is clear in pointing out that "a crucial attraction of postmodernist philosophical thought was that it placed reason and knowledge firmly in the context of social power" (Fricker 2009, 2). However, and as Fricker notes, rather than continuing to direct analysis at understanding how reason had come to be wielded as a weapon of power by the powerful, postmodernist thought instead continued down the track of critiquing reason itself. For Fricker, it is this choice of direction that has left an all-important gap in the knowledge of the degree to which reason has come to be used as a weapon, a gap she calls to be filled:

But we must not allow there to be mere silence where there was once a postmodernist buzz, for we can surely find other, better ways of discussing reason's entanglements with social power. What form, we might ask, should such discussion take? One answer to this question is that it should take the form of asking first-order ethical questions in the context of socially situated accounts of our epistemic practices. A socially situated account of a human practice is an account such that the participants are conceived not in abstraction from relations of social power (as they are in traditional epistemology, including most social epistemology) but as operating as social types who stand in relations of power to one another. This socially situated conception makes questions of power and its sometimes rational, sometimes counter-rational rhythms arise naturally as we try to account for the epistemic practice itself (Fricker 2009, 3, emphasis added).

The analysis being undertaken here of the silencing of the beneficiary in both historical and contemporary fiduciary relationships is arguably doing just as Fricker suggests. It is asking first-order ethical questions in the context of socially situated accounts of our epistemic practices and directly looking at social types who stand in relations of power to one another. This is a line of questioning Kantian fiduciary scholars have omitted from their ethical analyses, and it is a line of ethical questioning that sits at the very core of understanding the fiduciary relationship and its embedded social power.

\subsection{Epistemic Injustice and Social Power}

Fricker is explicit about the extent of the importance of the epistemic theory she outlines, noting that "the wrong of testimonial injustice cuts conceptually deeper than anything we had so far envisaged: a matter of exclusion from the very practice that constitutes the practical core of what it is to know" (Fricker 2009, 6). Carefully laying the conceptual groundwork of her project, Fricker launches her explanation of testimonial injustice with an initial discussion surrounding the definition of social power on which her project draws. The conception she uses is particularly useful to include here for two reasons: not only does it provide a richer explanation of Fricker's theory but it also serves to deliver the conceptual work of explaining the social power embedded in the relational infrastructure of the fiduciary. Summarising the concept she will put to work, Fricker defines social power as 
a practically socially situated capacity to control others' actions, where this capacity may be experienced (actively or passively) by particular social agents, or alternatively, it may operate purely structurally (Fricker 2009, 13).

In light of the fact that the fiduciary is premised on the arrangement that the trustee should act in the best interest of the beneficiary without the need for their prior consultation, and the fact that trustees are charged with making decisions on the beneficiaries' behalf, we can see how Fricker's concept of social power is at play in the fiduciary relationship. But the extent of this social power becomes all the more apparent when we also consider the first social context in which Fricker puts the social power concept to work-in identity power.

Choosing gender as one example of identity criteria, Fricker highlights how "an exercise of gender identity power is active when, for instance, a man makes (possibly unintended) use of his identity as a man to influence a woman's actions-for example, to make her defer to his word" (Fricker 2009, 14). This role that identity plays in activating social power in the context of the fiduciary contains significant weight when we consider, as has already been highlighted, that original trustees were male, thereby clearly exercising their identity power. But it holds additional weight when we also consider how contemporary judiciary decide if a fiduciary duty was ever present, as, for example, in times of dispute. In his paper, in which he attempts to lay out some guiding principles for identifying fiduciary relationships, Miller (2018, 7-8, emphasis added) notes the predominant use of two methods of identification-status-based and fact-based reasoning — outlining how the former tends to be the "default" position:

The prevalence of status reasoning is reflected in conventional wisdom about fiduciary law: one tends to think of fiduciary principles as attaching to persons by virtue of the legal or social role or position they occupy. Thus, we say that trustees, directors, agents, lawyers, and doctors are fiduciaries, and so too, by implication, we attach a fiduciary characterization to the relationships in which these persons perform their roles.

What Miller is arguably alluding to here is the social power implicitly afforded by judiciary to certain individuals by way of the legal or social roles they occupy, based on the social status such roles supposedly convey. And as has been highlighted elsewhere (Mussell 2020), it is roles that are deemed to hold reason as a central tenet that are afforded the social status Miller describes. This is both Fricker's identity power and "reason's entanglements with social power" in action. When we consider the asymmetrical power embedded in the fiduciary relationship-where beneficiaries are left unconsulted-we can start to see how social power accumulates. But what Miller is also arguably alluding to is the credibility that these social roles carry. It is this (arguably reason-based) credibility - afforded to individuals by way of their identity power from occupying certain social roles_-which ties back into Fricker's main theory of testimonial injustice. I now explain how.

\subsection{Fricker's Testimonial Injustice}

Having introduced identity power into her argument, Fricker then moves on to explaining its importance in the context of testimonial injustice, as well as 
highlighting the central role that stereotype plays in identity power. She is clear to note why identity power is an important and helpful epistemic device, allowing hearers to "use social stereotypes as heuristics in their spontaneous assessments of their interlocutor's credibility" (Fricker 2009, 16-17), and acknowledges that the use of stereotypes may in fact be proper and need not be detrimental. But Fricker's project is concerned with injustice, and as such, she draws attention to the effect and impact that a stereotype working against the speaker can have. When such prejudice is at play, she notes that "two things follow: there is an epistemic dysfunction in the exchange-the hearer makes an unduly deflated judgement of the speaker's credibility ... and the hearer does something ethically bad - the speaker is wrongfully undermined in her capacity as a knower" (Fricker 2009, 17).

We have already seen, as per Miller, how identity power can work in an agent's favour and produce what Fricker terms a credibility excess. The status-based reasoning used by judiciary to identify fiduciary relationships is an example of this. But as is Fricker's concern, the focus in this article is on the credibility deficit that occurs as a result of an "unduly deflated judgement of the speaker's credibility," the testimonial injustice to which it leads, and the wider implications for the epistemic agent violated as a result.

Bringing this back to the context of the beneficiary, it is helpful to remind ourselves of the social roles or positions that the original familial beneficiarieswomen and children - were afforded and to consider the identity power and credibility excesses or deficits associated with those roles. To recall Richardson's observation, "trusts arose in England primarily to protect family wealth and to provide for the wife and children, who were socially constructed as passive and dependent." As such, the beneficiaries of these trusts were women and children, and their social construction as passive and dependent was reinforced through the social roles and associated status the roles afforded. Specifically with regard to beneficiary wives, their dependency was premised on erroneous gender stereotypes simultaneously set within and arguably reinforced by a judicial system in which the legal doctrine of coverture existed-whereby a woman's legal right to own certain property was rescinded once she married (see Combs 2005; Erickson 2005). Coverture requires highlighting in this context of identifying epistemic injustice in the fiduciary, including identity power and credibility deficit, for a number of reasonsnot only because of the role it played in defining married women's rights to property ownership, thereby reinforcing dependency and positioning them as beneficiaries, but also because of the fallacious stereotypes it exposes when we note how feme sole, or unmarried women, were legally entitled to own both personal and real property and considered capable of making their own investment and financial decisions in its regard.

With this fallacious and inconsistent gender stereotype in the original fiduciary helpfully exposed, and the effect this has on ensuing identity power and credibility deficit highlighted, we can now move nearer towards identifying the specific sort of epistemic injustice embedded in the original fiduciary relationship as a sort of testimonial injustice - "a kind of injustice in which someone is wronged specifically in her capacity as a knower" (Fricker 2009, 20). This is a helpful honing of the 
subject matter. We are now starting to narrow down why an epistemic agent is discredited (owing to identity power and associated credibility deficit) and what, epistemically speaking, is being discredited (the agent's capacity as a knower). If we then contextualise this "capacity as knower" into the context of the fiduciary, and take into account Miller's point that trustees are often identified by judiciary using status-based reasoning and that the social roles judged as indicating the presence of a fiduciary relationship are deemed as involving high levels of reasoning capability, then the extension of this argument is that beneficiaries supposedly have less of this reasoning capacity and so are in need of the trustees to act on their behalf. Going a step further by taking into account the now much-maligned gender stereotypes of male-reason/female-emotion, alongside the well-established critiques of the construction of reason, such as Genevieve Lloyd's (1984) The Man of Reason, which argued that reason has been developed as an ideal constructed through the image of maleness, we start to see how female beneficiaries' credibility deficit specifically pertained to a perceived lack of reasoning capacity. And this of course takes us back to Fricker's earlier point of "asking first-order ethical questions in the context of socially situated accounts of our epistemic practices" to investigate and expose "reason's entanglements with social power."

But the analysis does not stop here. Because to recall, within the fiduciary relationship, the trustee is not required to consult with the beneficiary, and despite the trustee being tasked with acting in the beneficiaries' best interests, an articulation of their best interests is not requested. In short, the beneficiaries' testimony is not sought.

\subsection{Fricker's Pre-emptive Testimonial Injustice}

Whilst the core of Fricker's project is to deliver the theory of testimonial injustice, she also introduces readers to what she terms pre-emptive testimonial injustice. This branch of testimonial injustice is arguably best placed to explain the epistemic injustice of the silenced beneficiary within the fiduciary relationship.

Connecting with the previous point that testimonial injustice refers to an epistemic agent wronged specifically in her capacity as a knower, Fricker uses the work of Edward Craig - explicitly Knowledge and the State of Nature (1990), in which he seeks to elucidate why we have the concept of knowledge - to focus on the construct of the knower or, specifically, the "good informant." For Craig, "the explanation of why we have the concept of knowledge is that it arises from our fundamental need to distinguish good informants: originally, knowledge is what good informants can be relied on to share with us" (Fricker 2009, 130). Taking this a step further, Craig outlines the three different aspects that constitute a good informant as someone who can be relied on to share his or her knowledge, and Fricker helpfully summarises these as follows:

Someone who (1) is likely enough in the context to be right about what you want to know, (2) is communicatively open (principally, sincere) in what he tells you, and (3) bears indicator properties so that you can recognize that (1) and (2) are satisfied (130). 
It this third aspect of indicator properties that is of interest here, specifically in light of the previous discussions surrounding identity power and the credibility deficits associated with certain social identities and roles. As we have seen, gender is a well-known example of identity power. And as has been shown, women were (and clearly still are in certain contexts) socially positioned in passive and subordinated roles and subject to credibility deficits. Taking these two aspects together, alongside noting that within the fiduciary relationship, the trustee need not consult with the beneficiary or ask his or her opinion, we can conclude that the beneficiary is silenced and subjected to a related but different form of testimonial injustice. As Fricker (2009, 130, emphasis added) writes,

those social groups who are subject to identity prejudice and are thereby susceptible to unjust credibility deficit will, by the same token, also tend simply not to be asked to share their thoughts, their judgements, their opinions.... This kind of testimonial injustice takes place in silence. It occurs when hearer prejudice does its work in advance of a potential informational exchange: it pre-empts any such exchange. Let us call it pre-emptive testimonial injustice. The credibility of such a person on a given subject matter is already sufficiently in prejudicial deficit that their potential testimony is never solicited; so the speaker is silenced by the identity prejudice that undermines her credibility in advance. Thus purely structural operations of identity power can control whose would-be contributions become public, and whose do not.

To be clear, by not consulting with the beneficiary, who within the setting of the original familial fiduciary were women (and children), the beneficiaries' testimony is never solicited; so the speaker is silenced, and this takes place as a result of his or her identity and perceived credibility deficit. Indeed, by applying Fricker's pre-emptive testimonial injustice in this way to such a real-world example, we start to reveal the fiduciary's embedded relations of social power in action:

If we turn our imagination to the real social world and place the phenomenon of preemptive testimonial injustice in relations of social power, we readily see how it could function as a mechanism of silencing: not being asked is one way in which powerless social groups might be deprived of opportunities to contribute their points of view to the pool of collective understanding.... Testimonial injustice, then, can silence you by prejudicially pre-empting your word (Fricker 2009, 131, emphasis added).

The implications of thinking through this mechanism of silence in the context of the fiduciary carries even more weight when we consider how the construction of the fiduciary relationship is premised on such silencing: it is embedded in the fundamental structure of the relationship and delivers the asymmetrical power in the fiduciary, which has been discussed elsewhere (Mussell 2020). But the implication of this structural mechanism of silence as an epistemic injustice becomes all the more significant when we take into account its systematic nature (repeated and ongoing) and then also consider the resultant cumulative effects of this systematic use of the mechanism. Put differently, what are the long-term effects of deploying a mechanism of silence, of systematically silencing, and of being systematically silenced? 


\subsection{Consequences of Pre-emptive Testimonial Injustice}

With consideration to such implications, Fricker (2009, 145, emphasis added) offers some helpful reflections in this regard:

No wonder, then, that even relatively inconsequential testimonial injustices can carry a symbolic weight to the effect that the speaker is less than a full epistemic subject: the injustice sends the message that they are not fit for participation in the practice that originally generates the very idea of a knower.

Whilst Fricker's reflection is certainly helpful in starting to think through the consequences of testimonial injustice for an epistemic agent more generally, what she is not doing is focussing on the specific consequences of pre-emptive testimonial injustice, or indeed on the consequences of its systematic use and therefore cumulative effects. This is an important distinction to make when we consider the context of the fiduciary relationship being explicated here, which, as we have already seen, arguably has systematic pre-emptive testimonial injustice as a mechanism of silence embedded into its structure. However, in the absence of a more specific consideration from Fricker regarding the consequences of (cumulative) pre-emptive testimonial injustice on epistemic agents, her more general earlier statement will be briefly developed and then applied for the purposes of the fiduciary context.

Fricker's first point worth noting is that even relatively inconsequential testimonial injustices can carry a symbolic weight to the effect that the speaker is less than a full epistemic subject. What this invites us to do in the context of the fiduciary is evaluate whether the silencing of the beneficiary is indeed relatively inconsequential or if it in fact has more far-reaching consequences and so carries more than the symbolic weight suggested. Considering that the fiduciary relationship exists to ensure that the beneficiaries' best interests are met, it is safe to conclude that the pre-emptive testimonial injustice identified in the fiduciary does indeed have more far-reaching consequences (the beneficiaries own welfare) and so does in fact carry more than a symbolic weight regarding the beneficiary being less than a full epistemic subject. The outcome of this, as Fricker indicates, is the message that they (beneficiaries) are not fit for participation in the practice that originally generates the very idea of a knower, and in the case of pre-emptive testimonial injustice in the fiduciary, this clearly reflects the actual non-participatory and passive role in which the beneficiary is indeed permanently placed.

To summarise, whilst Fricker has helpfully engaged in considering the consequences of general testimonial injustice-which have been briefly developed above to consider the consequences of pre-emptive testimonial injustice-Fricker does not, however, comment on the possible long-term effects of cumulative pre-emptive testimonial injustice, of being systematically silenced. As indicated earlier, we can deduce the effects of pre-emptive testimonial injustice by assuming the same outcomes Fricker lays out for general testimonial injustice as described, but in the case of cumulative injustice, we must arguably exacerbate the extent of outcome due to extended circumstances. By doing so, we arrive at the position that silenced beneficiaries receive the repeated message, over a sustained period of time, that they are 
not fit to participate in the practice that originally generates the very idea of a knower practice and that they are not therefore a knower in this context.

The consequence of pre-emptive testimonial injustice delivering a reinforced and exacerbated message to beneficiaries that they are not fit for participation in the practice that originally generates the very idea of a knower provides a helpful analytical angle on a number of contemporary issues, specifically the persistent problem of few women in professional positions that constitute being a trustee and the widespread low levels of shareholder engagement and activism, both of which are addressed in the following section.

In addition, however, and again worth highlighting before the more in-depth discussion unfolds, is the crucial recognition that the application of Fricker's theory to the fiduciary relationship is exceptionally revelatory in bringing to the fore the extent to which pre-emptive testimonial injustice has permeated and fundamentally embedded itself in our financial systems and structures, the ongoing implications of which are both deep and far-reaching. It is to these discussions, and what they reveal of wider systemic injustice, that we now turn.

\section{PRE-EMPTIVE TESTIMONIAL INJUSTICE IN CONTEMPORARY CONTEXTS}

Another brief recap would be helpful at this point, to draw together the previous two sections and trace how they combine to help investigate ethical aspects embedded in the fiduciary - with a particular focus on epistemic injustice. To recall, the work of Kantian fiduciary scholars was first introduced to help shore up the argument that the fiduciary does indeed contain an ethical dimension. This was an important initial step to make in light of the increasing arguments made to the contrary, with some parties instead arguing that the fiduciary is reducible to being purely contractual. Despite some projects containing identified helpful elements, the seeming omission of Kantian fiduciary scholars to consider the historical development of the fiduciary, including questioning why the fiduciary was first devised, results in overlooking the power dynamic embedded in the relationship between trustees and beneficiaries, one rooted in gender politics and identity power. Whilst the fiduciary duty of care is identified as playing a central role, the possibility of utilising an Ethics of Care as an ethical framework for the fiduciary has been overlooked. By introducing this ethical framework and highlighting how its relational ontology and epistemology align well with the fiduciary as a relationship, this article, along with other work (Mussell 2020), remedies the issue. In addition, explicitly (re)framing the fiduciary as an ethical relationship - one unarguably premised on a power asymmetry in which the trustee makes decisions on behalf of the beneficiary without need for their prior consultation-helps focus an investigation on the identities and epistemic agency of the trustee and beneficiary. It raises a new line of questioning — of who gets to decide for whom, of who is silenced and why - and subsequently brings another ethical line of questioning to the fore, that of epistemic injustice, or, more specifically, preemptive testimonial injustice, embedded in the fiduciary relationship. 


\subsection{Updating to Contemporary Contexts}

Just as it has been shown to be fruitful to return to the historical foundations of the fiduciary to explicate the original power mechanism and related agential presuppositions embedded in the fiduciary relationship, so it is now also beneficial to explore how the fiduciary plays out in contemporary contexts. This will start to the bring to the fore the significantly wider contribution Fricker's work can make to business ethics.

As highlighted in the previous section, one consequence of pre-emptive testimonial injustice is that the epistemic agent receives a message that he or she is not fit to participate in the practice that originally generates the very idea of a knower practice. And if we consider the cumulative consequence of systematically receiving that message, then the result is that they come to consider themselves not fit to participate-the message affects their agency. Put differently, they are repeatedly disengaged from the decision-making process and, as a result, become apathetic and are disempowered. As an epistemic agent whose thoughts, opinions, or judgements are systematically not sought, and whose testimony is not seen as requisite or necessary for consultation, then any capability or capacity to influence-any power to determine decision-making - is removed. And, as a result of their exclusion from the decision-making process over a sustained period of time, the epistemic agent arguably comes to assume that he or she is, as Fricker notes, not fit to participate in the practice and is in fact not a knower.

Looking to contemporary contexts for evidence of where this sort of repeated and reinforced disengagement may exist-for examples of how beneficiaries have become cumulatively disempowered due to their testimonies not being sought, along with the long-term consequences of this exclusion - we can indeed find some interesting examples.

\subsection{Persistently Few Female Trustees}

When we consider the cumulative effect of pre-emptive testimonial injustice in the original familial context, where women were socially constructed as passive and dependent beneficiaries, we start to develop an interesting insight into wider social practice at play, including how the repeated message of not being fit to participate still pervades present-day practice. This is particularly enlightening when we consider the contemporary focus on why there is such a dearth of participation of women in senior leadership positions in organisations, that is, in senior management teams or on boards, where such roles position them as trustees, with shareholders as beneficiaries. It also elucidates why the finance sector continues to be male dominated, with particular roles, such as investment managers ${ }^{3}$ and trustees of small trusts-both of which have fiduciary duties at their core-having so few women in position. ${ }^{4}$ When we take into account the normative power that cumulative

\footnotetext{
${ }^{3}$ See the Alpha Female Citywire (2018) report indicating that of 16,084 fund managers in its database, only 1,662 (10.3 percent) were female.

${ }^{4}$ David O'Sullivan to Mark Potter, letter regarding feedback on the consultation on future of trusteeship and governance, September 24, 2019, https://shareaction.org/wp-content/uploads/2019/10/Pension-Regula tor\%E2\%80\%99s-consultation-on-trusteeship-and-governance.pdf: "The finance sector remains male-
} 
pre-emptive testimonial injustice has been shown to have on an epistemic agency, alongside the sheer length of time that women have been precluded from assuming positions of trusteeship, a new light is shone on this persistent issue. In short, in professions where the fiduciary is prevalent, and in senior-level positions in organisations that constitute trusteeship, there is a strong gender bias to be found, often along with highly masculinised organisational culture (McDowell 1997; Mussell 2018). The application of Fricker's work, then, is invaluable in revealing how the cumulative effects of systematic pre-emptive testimonial injustice embedded in the fiduciary are playing out in contemporary international board rooms and beyond.

\subsection{Shareholder Activism and Active Ownership as Pre-emptive Testimonial Pushback}

There is, however, another example of where the cumulative consequences of silencing the beneficiary are playing out, and in fact, there are signs of increasing discontent at the disempowerment being imposed - signs of shareholder engagement and activism. Shareholder activism, or active ownership, takes many forms. It can involve a solo shareholder with a significant number of shares working alone to try to influence decision-making within the organisation he or she partly owns, or it can involve a group of shareholders working together to likewise influence trustees. ${ }^{5}$ Shareholder activism can also take place via a third party, that is, a trustee, such as a pension fund manager, who is acting on beneficiaries' behalf. In addition, the format the activism takes varies, with some engagement taking place via private meetings (Coskun et al. 2018), whilst other activity is public, executed at shareholder meetings. Although the agent configurations and format may vary, as indeed does the shareholders' motivation for pursuing activism (i.e., financially motivated or non-financially motivated, also known as social shareholder engagement [SSE] with the objective to advance social and/or environmental issues; see Goodman and Arenas 2015; Cundill, Smart, and Wilson 2018), the fundamental issue remains the same: the objective of shareholder activism is to ensure the beneficiaries' voices are heard. It is to demand that their thoughts, judgements, and opinions be un-silenced. It commands their consultation. It transitions the beneficiary from the passive and subordinated position highlighted by Richardson to one of an engaged agent, the implications of which are only now becoming clear. As Lisa Fairfax $(2019,1301)$ writes,

the shift away from shareholder apathy reflects a radical departure from the traditional corporate governance norm of shareholder passivity. While many corporate governance experts have conceded the descriptive shift away from shareholder apathy (at least temporarily), few have acknowledged the normative shift and its related significance.

\footnotetext{
dominated across the board; for example a study of small trusts in the UK found $84 \%$ of trustees are male. The disconnect between trustee board priorities and the wider membership base is not surprising." The author references Smith (2014).

${ }^{5}$ For an example of such group activity, see the recent activity of Amazon employees who recently used their company-issued shares to propose a resolution asking the company to report on its plans to help tackle climate change; see https://www.wired.com/story/amazon-employees-try-new-activism-shareholders/.
} 
This development in shareholder activism - both financially and non-financially motivated -is particularly interesting in light of the application of Fricker's theory to the fiduciary, in which the beneficiaries' silencing is theorised as pre-emptive testimonial injustice. Indeed, by utilising this application, we can see how shareholder activism can be read as shareholder pushback, rooted in issues concerning epistemic injustice. The objective of the activism-irrespective of its motivation-is to engage, to influence, and to empower beneficiaries, to move from testimonial exclusion to inclusion, from injustice to justice.

It is particularly worth highlighting at this point, in the context of giving voice to the previously voiceless, that the amount of shareholder activism varies according to motivation, and this differential commands comment. Financially motivated shareholder activism is more commonplace with a longer history, has propensity to take place via private meetings, and has been studied more widely (Cundill, Smart, and Wilson 2018). SSE, by comparison, is a relatively new phenomenon, has relatedly been subject to less investigation, and takes place with less frequency. Its motivation also often stands in contrast to that of financially motivated shareholder activism, a point highlighted by Goodman and Arenas $(2015,163)$ :

The shareholder primacy orientation of traditional agency theory assumes shareholders will maximise their individual utility (Jensen \& Meckling, 1976). Social shareholder engagement (SSE) poses a challenge to this approach, as shareholders bring the concerns of often voiceless and marginalised stakeholders, such as victims of human rights abuses and environmental degradation, to the heart of corporate decision making.

That it has taken time for SSE to gather ground should be of no surprise. Firstly, and as Goodman and Arenas (2015) note, SSE poses a challenge to orthodox economic theory that insists economic agents (caricatured in ideal types such as homo economicus) will seek utility maximisation. As such, SSE sets out a similar contest to that of socially responsible investments, in questioning these orthodox premises, a challenge which has been commented on elsewhere (see Mussell 2018). Secondly, as such economic premises have become embedded in widely held beliefs, it has only been through relatively recent enquiry, including the Freshfields Bruckhaus Deringer (2005) report, that the legal possibility of trustees being able to take into account non-financial criteria in their fiduciary duty has become possible. It is a considerable achievement that only fourteen years after the publication of the Freshfields report, regulations came into effect on October 1, 2019, in the United Kingdom requiring pension fund trustees to have a policy on how their investments take into account environmental, social, and governance issues, including climate change. ${ }^{6}$ And thirdly, the extent of shareholder ownership disconnect arguably plays a central role in the "shareholder apathy" coined by Fairfax. The majority of shareholders with institutional investments via pension funds do not know which companies or industries their money is invested in. They have been, and still are,

\footnotetext{
${ }^{6}$ See Shareaction press release on fiduciary duty: "Responsible Investment Regulations Come into Force for Trustees," October 1, 2019, https://shareaction.org/responsible-investment-regulations-come-into-force/.
} 
repeatedly disengaged from that information, precluded from consultation. And one reason why they do not know, nor seek to become knowers, is arguably because they have repeatedly received the message that they are not fit to participate in the practice that originally generates the very idea of a knower practice.

\subsection{Shareholder Activism: Refreshing the Fiduciary}

What, then, in light of the application of Fricker's theory of pre-emptive testimonial injustice to the position of the silenced beneficiary, are the implications of increased shareholder activism on the fiduciary relationship? What are the consequences of this increased level of engagement, of this command to be consulted, on the asymmetrical power dynamic embedded in the fiduciary? And how does this command to be consulted disrupt the original presuppositions regarding beneficiary capabilities upon which the fiduciary was originally premised?

As has previously been discussed, the effect of cumulative pre-emptive testimonial injustice on an epistemic agent is the repeated delivery of the message that the agent is not fit to participate in the practice that originally generates the very idea of a knower practice. The consequence of that repeated delivery is to normalise the message. That this has indeed been the outcome in the context of the beneficiary is illustrated by Fairfax $(2019,1322)$, who writes,

Historically, governance experts pointed to the fact that shareholders were not active as clear evidence that shareholders did not believe that they ought to be active. In this respect, shareholder apathy itself served as the compelling evidence that shareholders had a normative preference for apathy.

Later Fairfax added,

Some suggested that one reason for this continued embrace of apathy was shareholders' continued belief that activism was not normatively appropriate. This means that the apathy norm was so powerful that shareholders continued to embrace it even when such embrace may not have been in their best interests (1323, emphasis added).

This observation in the context of shareholder activism is quite remarkable. It clearly demonstrates the deep reach of pre-emptive testimonial injustice on the beneficiary. This example also provides a valuable insight into the long-term effects of systematic epistemic injustice on epistemic agents and the degree to which this becomes embedded and normalised in behaviour. With this in mind, the fact that shareholder activism is now gaining momentum carries even more weight, and to recall Fairfax's words, "few have acknowledged the normative shift and its related significance" - particularly when we can now read it as pre-emptive testimonial pushback.

When we add this observation to the earlier revelation regarding presuppositions of the beneficiaries' agential capabilities embedded in the fiduciary, we start to see a more realist reassessment of those capabilities and a fundamental shift in the power dynamic of the fiduciary relationship. Indeed, Fairfax's $(2019,1345)$ article delivers the conclusion that 
Shareholders and directors have come to accept the propriety of shareholder voice and influence. They have come to believe that shareholders can and should play a role in holding directors accountable and shaping corporate practices.

This inclusive approach, which appears to reject the previously outlined assumptions of beneficiaries' credibility deficit, clearly marks a considerable change to the original beliefs on which the familial fiduciary was premised and seemingly starts to remedy the epistemic injustice identified as embedded in its original architecture. It suggests that a challenge to the power dynamic of the trustee over the beneficiary is gaining increasing momentum, potentially creating space for a rethink of the fiduciary and related theory, a point to which I shortly return after firstly addressing wider systemic implications.

\subsection{Identifying Systemically Embedded Pre-emptive Testimonial Injustice and the Reach of Fricker's Contribution}

As already noted, fiduciary has played, and continues to play, a fundamental role in all financial and business organisations. It is a legal concept with a deep and long history. The evolution of this concept over hundreds of years, and its appropriation from use in familial to corporate law, has resulted in a great depth and breadth of its use, and it is now fundamentally embedded in financial systems, institutions, and organisations and sits at the core of the way in which they function. The fiduciary steers and constrains decision-making. When its increasingly narrow economic interpretation is used in conjunction with supposedly shareholder-centric theory, such as the shareholder primacy model_- "supposedly" because the latter has clearly failed to identify the systematic silencing and exclusion of the beneficiary that sits at the centre of its structure-we can start to see how the identified epistemic injustice, of not being sought and being silenced, has resulted in a fundamental fault in the system, delivering an epistemic disjuncture. We have agents acting on behalf of principals without engaging them in consultation, whilst applying particular economic reasoning with which the principal may well not concur, and principals largely assuming that they are not fit to participate.

When we take into account the exhaustive use of the fiduciary as a legal device, in conjunction with the outlined identification of pre-emptive testimonial injustice being embedded in its fundamental structure, we can start to clearly bring to the fore the extent to which existing financial systems, institutions, and organisations have this injustice firmly embedded within them. Another example of this in play is the highly stratified structure of current financial systems, with increasing layers of (often highly lucrative) fiduciary intermediaries further separating beneficiaries from trustees, another layer of "expert trustees" reinforcing the message that beneficiaries are not fit to participate in the process. This increasingly complex intermediary issue is discussed in greater detail elsewhere, specifically in the context of how potential solutions using blockchain technology for corporate governance potentially facilitate shareholders voting directly (Yermack 2017; Van der Elst and Lafarre 2019).

That inequalities and injustices exist in financial and corporate institutions is not of course a situation that has gone unnoticed. Too many authors to mention here, 
from disciplines spanning political economy, development studies, gender studies, business ethics, international relations, and so on, have visited this arena before. But explicit connections between recognised inequalities and injustices being pinpointed to the fiduciary arrangement embedded in these institutions are limited. That it is cumulative pre-emptive testimonial injustice in the fiduciary relationshipwhich to recall is premised on an unequal power distribution-giving rise to such injustice and inequality, is overlooked. This situation should come as no surprise when we consider how entrenched the legal device of the fiduciary has become, undoubtedly owing to its enormous success (in monetary terms) of expanding global capitalism and financial markets, via facilitating remote shareholder ownership and financial investments. It simply exists all around us. It is a legal device, a mechanism that has a long history of service and use, and as a result, it now sits in the shadows of the systems it serves, a tried, tested, and trusted tool.

That the fiduciary often escapes the analytical eye outside of legal studies, even when the author specialises in issues relating to injustice, gender, and finance, evidences how elusive the concept can be. Providing a clear example will be helpful. In her excellent and otherwise comprehensive book The Gendering of Global Finance, Libby Assassi (2009) delivers a helpful and detailed account of how contemporary financial institutions and systems are imbued with gender inequality. And in her introduction, she specifically draws attention to systemic issues, writing that "the possibility of gendered and subordinating structures being present in the workings of global finance is an area which has been consistently overlooked" (2). Tracing the shift from feudalism to capitalism, the emergence of credit and financial institutions, and the rise of global financial markets, she draws out the gender inequalities that permeate the process she describes. Yet, despite the in-depth discussion she outlines, including a chapter titled "Property and Gender: Irrational Women and Rational Men," no focus on the fiduciary unfolds. It is absent from the analysis. There is no mention of the beneficiary as subordinated in the structure of the fiduciary relationship and no discussion that the fiduciary is a gendered and subordinating structure present in the workings of global finance. The injustice embedded in the fiduciary is seemingly out of view even from those who set out to seek it.

\subsection{Familiar but Flawed: Is the Fiduciary Future-Fit?}

Now that the fiduciary has been identified as being premised on pre-emptive testimonial injustice, with problematic cumulative effects, and the extent to which this embedded injustice has gone undiscovered-even by primed eyes-has been noted, how then to move forward? What options are available to correct this injustice? Here it would be helpful to refer back to Assassi, who in turn draws on prior thinking regarding proposed remedies for dealing with identified systemic exclusion, silencing, and injustice. She writes that "Nannerl Keohane once famously stated 'In women's studies, a good piece of conventional wisdom holds that it is simply not enough to "add women and stir"' (Keohane 1982, 87). In terms of the gendered construction of financial markets, it too has to be said, it is simply not enough to 'add women and stir'" (Assassi 2009, 130). 
Can the same wisdom work in this situation? Can we simply "add shareholders and stir"? Will this accommodate the "propriety of shareholder voice and influence" that, according to Fairfax, both shareholders and directors have come to accept? In a normative fiduciary relationship, premised on an asymmetrical power dynamic of trustees/directors dominating beneficiaries/shareholders, where cumulative preemptive testimonial injustice has normalised the silencing of billions of shareholders (and other beneficiaries), is it really possible to retain that same injustice-inducing structure to accommodate the "new belief" that "shareholders can and should play a role in holding directors accountable"? If the now identified injustice in the fiduciary, and its ensuing implications for further injustice, has been so deeply embedded in its structure as to go unnoticed, then how deeply embedded is the thinking that the trustee truly knows best and beneficiaries need not be consulted? What latitude exists in the current arrangement for shareholders really to hold directors accountable? We have already seen the extent to which the gendered origins of the fiduciary arrangement have had a long-term normative effect and are deeply entrenched in financial systems and institutions, resulting in a highly masculinised institutional culture (McDowell 1997) and a dearth of women's voices in trustee positions, and what the silencing effect that cumulative pre-testimonial injustice has had on the engagement of shareholders as beneficiaries. When the existing legal device has consistently delivered the message that shareholders are not fit to participate in the practice that originally generates the very idea of a knower practice, is it really viable to suggest that shareholders can now be told their voice matters and that these can now simply be added to the existing processes, systems, and structures that have evolved around their exclusion? Or is it time, now that the epistemic injustice hidden in the fiduciary has been called out of the shadows, to challenge if it is in fact futurefit? Whilst others may advocate that "fiduciary law must be repaired before it can properly carry out its role in regulating financial entrustment and management" (Getzler 2014), the preceding analysis revealing the epistemic injustice embedded in the fiduciary dynamic could arguably preclude that possibility.

The increasingly inclusive and accepting approach highlighted by Fairfax could potentially make way for the development of a new arrangement, an alternative conceptualisation of the fiduciary - an arrangement in which the trustee and beneficiary are situated in a more active and consultative relationship, one that moves away from the obscurity caused by beneficiaries being cast in an archaic passive role, a reconceptualisation that moves away from the passive rhetoric of beneficiary rights that require "protection" towards a refocus on their active ownership, along with the relational responsibilities towards the natural world and wider society that this entails.

\section{CONCLUSION}

This article has fundamentally delivered an ethical project, one that starts to demonstrate the breadth of contribution that Miranda Fricker's work can make to business ethics. Applying Fricker's work on epistemic injustice to elucidate the position of the silenced beneficiary in the fiduciary relationship has highlighted the implications of long-term pre-emptive testimonial injustice and demonstrated the far-reaching effect 
this has had on limiting the agency of beneficiaries. By doing so, the project has been able to shed light on why there are so few females in positions of trusteeship and on why beneficiaries have been reticent in being active shareholders-remaining widely disengaged and silent. The article has also revealed the breadth and depth of the scale to which epistemic injustice is built into our current financial architecture because of the embeddedness of this legal concept in current financial systems and structuresagain reiterating the wide potential of Fricker's work in a business ethics context.

As one generation uses and appropriates concepts from its predecessors, so the history of the development of those concepts is forgotten. The socioeconomic contexts that helped shape the concepts' development become embedded, rendered implicit, as more contemporary applications of the concept take centre stage.

The objective of analysing the concept of the fiduciary with Fricker's work has been to rediscover and reinterpret its ethical narrative, to show how fiduciary's power dynamic, originally built on dubious gender stereotypes and epistemic injustice, is increasingly coming under challenge to refresh and develop into a future-fit fiduciary.

\section{Acknowledgements}

Acknowledgements are due to the Cambridge Political Economy Society Trust for its generous financial support assisting with the initial thinking underpinning this article and to Professor Simon Deakin for introducing me to the legal concept of the fiduciary and its great potential for social ontological and ethical analysis. I also wish to convey thanks to the two anonymous reviewers for their kind words and invaluable input in helping the article take its final shape and to the editorial team of this special edition of $B E Q$, whose steer has been most helpful.

\section{REFERENCES}

Assassi, Libby. 2009. The Gendering of Global Finance. Basingstoke, UK: Palgrave Macmillan.

Citywire. 2018. Alpha Female 2018. https://citywire.co.uk/Publications/WEB_Resources/ Creative/Global/Alpha-Female-2018.pdf.

Combs, Mary Beth. 2005. “A Measure of Legal Independence: The 1870 Married Women's Property Act and the Portfolio Allocations of British Wives." Journal of Economic History 65(4): 1028-57.

Coskun, Hülgen, Jana Oehmichen, Michael Wolff, and Laura Jacobey. 2018. "Let's Talk Fact to Face-Antecedents of Succesful Private Shareholder Activism in a Global World." Academy of Management Proceedings 1. DOI: 10.5465/AMBPP.2018.18341.

Craig, Edward. 1990. Knowledge and the State of Nature: An Essay in Conceptual Synthesis. Oxford: Clarendon Press.

Cundill, Gary J., Palie Smart, and Hugh N. Wilson. 2018. "Non-financial Shareholder Activism: A Process Model for Influencing Corporate Environmental and Social Performance." International Journal of Management Review 20(2): 606-26.

Erickson, Amy Louise. 2005. “Coverture and Capitalism.” History Workshop Journal 59(1): $1-16$.

Fairfax, Lisa. 2019. "From Apathy to Activism: The Emergence, Impact, and Future of Shareholder Activism as the New Corporate Governance Norm." Boston University Law Review 99(1): 1301-45. 
Freshfields Bruckhaus Deringer. 2005. A Legal Framework for the Integration of Environmental, Social and Governance Issues into Institutional Investment. Geneva: United Nations Environment Programme (UNEP) Finance Initiative.

Fricker, Miranda. 2009. Epistemic Injustice: Power and Ethics of Knowing. Oxford: Oxford University Press.

Getzler, Joshua. 2014. "Financial Crisis and the Decline of Fiduciary Law." In Capital Failure: Rebuilding Trust in Financial Services, edited by Nicholas Morris and David Vines, 1-17. Oxford: Oxford University Press.

Gold, Andrew S., and Paul B. Miller. 2014. Introduction to Philosophical Foundations of Fiduciary Law, edited by Andrew S. Gold and Paul B. Miller, 1-17. New York: Oxford University Press.

Goldstone, Hartley, Scotty McLennan, and Keith Whitaker. 2013. "The Moral Core of Trusteeship: How to Develop Fiduciary Character." Trusts and Estates, May, 49-52.

Goodman, Jennifer, and Daniel Arenas. 2015. "Engaging Ethically: A Discourse Perspective on Social Shareholder Engagement." Business Ethics Quarterly 25(2): 163-89.

Jensen, M. C. and Meckling, W., H. 1976. "Theory of the Firm: Managerial Behavior, Agency Costs and Ownership Structure.” Journal of Financial Economics 3(4): 305-360.

Keohane, Nannerl. O. 1982. "Speaking from Silence: Women and the Silence of Politics". In A Feminist Perspective in the Academy, edited by Elizabeth Langland and Walter. R. Gove. Chicago, IL: University of Chicago Press.

Laby, Arthur T. 2005. "Juridical and Ethical Aspects of the Fiduciary Obligation." Annual Review of Law and Ethics 13: 565-87.

Lloyd, Genevieve. 1984. The Man of Reason: "Male" and "Female" in Western Philosophy. London: Routledge.

Lydenberg, Steve. 2014. "Reason, Rationality and Fiduciary Duty." In Cambridge Handbook of Institutional Investment and Fiduciary Duty, edited by James P. Hawley, Andreas G. F. Hoepner, Keith L. Johnson, Joakim Sandberg, and Edward J. Waitzer, 287-99. Cambridge: Cambridge University Press.

McDowell, Linda. 1997. Capital Culture: Gender at Work in the City. Oxford: Blackwell.

Miller, Paul. 2014. "The Fiduciary Relationship." In Philosophical Foundations of Fiduciary Law, edited by Andrew S. Gold and Paul B. Miller, 63-90. New York: Oxford University Press.

Miller, Paul. 2018. “The Identification of Fiduciary Relationships.” In The Oxford Handbook of Fiduciary Law, edited by Evan J. Criddle, Paul B. Miller, and Robert H. Sitkoff. New York: Oxford University Press.

Mussell, Helen. 2018. "Who Dares to Care? (In the World of Finance)." Feminist Economics 24(3): 113-35.

Mussell, Helen. 2020. "Leadership and the Fiduciary: Addressing Asymmetrical Power by Caring Well." In Paradoxes of Leadership and Care: Critical and Philosophical Reflections, edited by Leah Tomkins, 86-97. Cheltenham, UK: Edward Elgar.

Richardson, Benjamin J. 2011. "From Fiduciary Duties to Fiduciary Relationships for Socially Responsible Investing: Responding to the Will of Beneficiaries." Journal of Sustainable Finance and Investment 1(1): 5-19.

Samet, Irit. 2014. "Fiduciary Loyalty as Kantian Virtue." In Philosophical Foundations of Fiduciary Law, edited by Andrew S. Gold and Paul B. Miller, 125-40. New York: Oxford University Press.

Sandberg, Joakim. 2011. "Socially Responsible Investment and Fiduciary Duty: Putting the Freshfields Report into Perspective.” Journal of Business Ethics 101(1): 143-62. 
Sandberg, Joakim. 2013. “(Re-)interpreting Fiduciary Duty to Justify Socially Responsible Investment for Pension Funds?" Corporate Governance: An International Review 21 (5): 436-46.

Smith, I. 2014. "Pensions Trust Reflects on Trustee Election after Diversity Move." Pensions Expert, November 14. https://www.pensions-expert.com/DB-Derisking/PensionsTrust-reflects-on-trustee-election-after-diversity-move.

Van der Elst, Christoph, and Anne Lafarre. 2019. "Blockchain and Smart Contracting for the Shareholder Community." European Business Organization Law Review 20(1): 111-37.

Yermack, David. 2017. “Corporate Governance and Blockchains.” Review of Finance 21(1): 7-31.

Helen Mussell (hjm47@cam.ac.uk) is a lecturer in management, employment, and organisation at Cardiff Business School, Cardiff University, and a research associate at the Centre for Business Research, Judge Business School, Cambridge. Mussell holds an MPhil and PhD in gender studies from the University of Cambridge, where she was Cambridge Political Economy Society Trust Scholar (2012-16). Her work is highly interdisciplinary and includes publications across philosophy (ethics, epistemology, and ontology), heterodox economics, business ethics, gender studies, feminist jurisprudence, and social psychology.

This is an Open Access article, distributed under the terms of the Creative Commons Attribution licence (http://creativecommons.org/licenses/by/4.0/), which permits unrestricted re-use, distribution, and reproduction in any medium, provided the original work is properly cited. 